\title{
Evaluation of the predisposition and clinical impact of BK virus replication in kidney transplant patients
}

\author{
ELVIANI B. MOURA ${ }^{1,2}$, SILVIA V. PETZHOLD ${ }^{3}$, AUGUSTO R. AMARAL ${ }^{4}$, \\ LUCIANE M. DEBONI ${ }^{2}$ and PAULO H.C. DE FRANÇA ${ }^{3,4}$ \\ ${ }^{1}$ Departamento de Enfermagem, Universidade da Região de Joinville/UNIVILLE, \\ Rua Paulo Malschitzki, 10, 89219-710 Joinville, SC, Brazil \\ ${ }^{2}$ Fundação Pró-Rim, Rua Xavier Arp, 15, 89227-680 Joinville, SC, Brazil \\ ${ }^{3}$ Departamento de Farmácia, Universidade da Região de Joinville/UNIVILLE, \\ Rua Paulo Malschitzki, 10, 89219-710 Joinville, SC, Brazil \\ ${ }^{4}$ Departamento de Medicina, Universidade da Região de Joinville/UNIVILLE, \\ Rua Paulo Malschitzki, 10, 89219-710 Joinville, SC, Brazil \\ Manuscript received on July 19, 2016; accepted for publication on January 19, 2017
}

\begin{abstract}
The BK virus (BKV) produces a subclinical kidney infection in immunocompetent individuals. However, viremia may occur in kidney transplant patients with ongoing immunosuppression. BKV-associated nephropathy (BKVN) has no specific treatment and is a leading cause of organ transplant loss. In this study, we evaluated the predisposition and the clinical impact of BKV replication in kidney transplant patients during post-transplant monitoring in a reference institution in Brazil. Demographic, clinical and laboratory data generated during routine outpatient follow-up were retrospectively collected. BK viremia was investigated using real-time polymerase chain reaction. Of the 553 participants, $7.4 \%(n=41)$ presented BKV replication. Of these, 16 (39\%) lost their kidney graft and interstitial nephritis was identified on kidney biopsy in $50 \%$ of the cases. Among the evaluated variables, only the use of the immunosuppressant mycophenolate sodium was identified as a risk factor for viremia (OR 7.96; 95\% CI 2.35 to 26.98). The graft survival estimate in BKV-positive patients was significantly reduced (24.8\% vs. $85.6 \%)$ after 10 years of transplantation. We concluded that defining predisposing factors remains an important challenge for the prevention and control of BKV activity following kidney transplantation, especially considering the development of BKVN and its strong effect on graft maintenance.
\end{abstract}

Key words: BK virus, nephropathy, renal transplantation, viremia.

\section{INTRODUCTION}

Kidney transplantation is considered to be the best method of treatment for patients with chronic kidney

Correspondence to: Paulo Henrique Condeixa de França

E-mail: ph.franca@univille.br

* Contribution to the centenary of the Brazilian Academy of Sciences. failure. Transplantation provides the patients with a better quality of life and full reintegration into daily activities in addition to increasing their life expectancy and representing the most cost effective option (Alvares et al. 2011, Harada et al. 2009). Despite the numerous scientific and technological advances aimed at prolonging kidney graft survival, 
the recurrence of chronic nephropathy and both long and short term graft loss have been attributed to the development of opportunistic infections, especially BK virus (BKV) infection (Egli et al. 2007).

Infection with $\mathrm{BKV}$, which belongs to the Polyomaviridae family, usually occurs in childhood. After primary infection, the virus remains latent and presents tropism for the urinary tract (Silva et al. 2011). Typically, reactivation of the polyomavirus only occurs in cases of autoimmune disease and in immunocompromised individuals, such as those infected with the human immunodeficiency virus (HIV) and solid organ transplant patients because these conditions involve altered immune systems (Manitpisitkul et al. 2009). Although infection is generally asymptomatic, active infection may result in viremia and viruria (Silva et al. 2011).

BKV-associated nephropathy (BKVN) is associated with high morbidity and mortality and is the most common viral disease that affects the kidney graft parenchyma. BKVN may cause graft dysfunction, premature failure and loss (Hirsch et al. 2013). It has a prevalence of 1 to $10 \%$ and leads to permanent graft dysfunction or loss in $40 \%$ to $60 \%$ of cases (Bassil et al. 2014, Dekeyser et al. 2015). All kidney transplant recipients with $\mathrm{BKV}$ replication have variable deteriorating graft function, which is manifested as an increase in serum creatinine (Ramos et al. 2002).

The risk factors for BKV reactivation are not completely understood but may include factors related to the donor, recipient, kidney graft and type of immunosuppression used (Medeiros et al. 2008, Huang et al. 2014). Among other variables, a weakened immune status, advanced age, male gender, Caucasian ethnicity and diabetes have been proposed as risk factors for BKV manifestation (Zalona et al. 2013). Furthermore, the immunosuppression load administered after transplantation has been reported to be the primary risk factor for BKVN development (Boothpur and Brennan 2010).

BKVN is a growing problem in the kidney transplant recipient population (El Ansary et al. 2016). There is no specific treatment for BKVN, and evolution to graft loss requires that the patient returns to the kidney replacement therapy program, which raises the associated costs. These are the main reasons that this phenomenon has been studied in transplant centers worldwide (Siguier et al. 2012, Mbianda et al. 2015). The aim of the study was to investigate the prevalence of and the predisposing factors for BKV replication after kidney transplantation and the ensuing clinical outcome.

\section{MATERIALS AND METHODS}

\section{STUDY TYPE AND TARGET POPULATION}

This study was a cross-sectional observational study based on the collection, analysis and correlation of the retrospective demographic, clinical and laboratory data generated during routine clinical visits from patients undergoing kidney transplantation. The study was approved by the University of Region of Joinville Research Ethics Committee (reference no. 830,565).

The study included kidney transplant patients undergoing post-transplant monitoring at the Pró-Rim Foundation who underwent bimonthly samplings for the investigation of BKV viremia after transplantation. Pró-Rim Foundation is an outpatient clinic located in Joinville, Santa Catarina, southern Brazil, which coordinated over 1,400 transplantations since its foundation in 1978, reaching a mean annual number of 85 in the last five years.

\section{INVESTIGATION OF VIREMIA}

Five $\mathrm{mL}$ of peripheral blood was collected from each patient in a bottle containing the anticoagulant ethylenediaminetetraacetic acid. Viral DNA was 
extracted using the Biopur Mini Spin Plus 250 kit (Biometrix, Curitiba, Brazil). BK viremia was investigated using the real-time polymerase chain reaction technique with the BKV Q-PCR Alert kit (Nanogen Advanced Diagnostics, Torino, Italy), which has a detection limit of 10 genome equivalents $/ \mathrm{mL}$.

\section{DEMOGRAPHIC, CLINICAL AND LABORATORY} DATA

The necessary data were obtained by consulting the medical records. Study variables were divided into demographic (age and gender), clinical (underlying disease, immunosuppression regimen, type of substitutive kidney therapy prior to transplant, donor type (alive or dead) and number of transfusions) and laboratory data (antibody reactivity panel count [ARP], blood type, serum creatinine level and post-transplant kidney function). Based on locally established practice, a serum creatinine level greater than $2.5 \mathrm{mg} / \mathrm{dL}$ at discharge was considered a poor prognosis of kidney function. Similarly, the kidney graft was considered to be functioning in the immediate post-transplant period when urine output and a reduction in the serum creatinine level were observed. Also based on local practice, kidney biopsy was recommended for patients presenting two sequential positive results of viremia analysis.

\section{STATISTICAL ANALYSIS}

Statistical tests were performed using SPSS (Statistical Package for the Social Sciences, SPSS Inc., Chicago, IL, USA) software version 17.0. The differences between the proportions shown in Table I were tested for significance using the Chi-square test with Yates correction, Fisher's exact test or T-test when appropriate. $P$ values equal to or less than 0.05 were deemed significant based on a $95 \%$ confidence interval.

Multivariate analysis of the risk predictors shown in Table II was performed with binomial logistical regression with a $95 \%$ confidence interval. The descriptive analyses shown in Table III were performed without the use of statistical analysis. The survival analysis shown in Figure 1 was performed using the Kaplan-Meier curve, and the comparison of curves was performed using the weighted log-rank test.

\section{RESULTS}

A total of 702 patients were under outpatient monitoring during the study period. The established inclusion criteria led to the enrollment of 553 (78.8\%) kidney transplant recipients, including 359 men $(41.4 \pm 13.2$ years old $)$ and 194 women (41.3 \pm 13.3 years old). Forty-one (7.4\%) patients tested positive for post-transplantation BKV replication. The mean age in this group was $42.5 \pm 11.0$ years old, with males (73.2\%) and blood type A (48.8\%) being prevalent. Table I shows the distribution of BK viremia cases according to the demographic, clinical and laboratory characteristics.

Most patients received graft from deceased donors (69.3\%) and had an ARP between 0 and $50 \%(92.4 \%)$. Immediate post-transplantation kidney function $(P=0.81)$ and the $2.5 \mathrm{mg} / \mathrm{dL}$ serum creatinine threshold at discharge $(P=0.09)$ did not differ between the BKV-negative and BKVpositive patient groups. The immunosuppressant mycophenolate sodium (MPS) was significantly more represented among patients with posttransplantation BKV replication (85.4\%; $P<0.01)$. Only one patient (2.2\%) among those with exclusively cyclosporine-based (CsA) or azathioprine-based $(\mathrm{n}=46)$ immunosuppression had post-transplantation BK viremia, whereas this positivity reached $7.9 \%(n=40)$ in patients administered other immunosuppressants $(\mathrm{n}=507)$.

Table II shows the distribution of patients according to post-transplant BKV replication and the demographic, clinical and laboratory data proposed in some studies as BKVN predictors in kidney transplant patients. 
TABLE I

Pre and post-transplant patient characteristics according to negative (-) or positive $(+)$ post-kidney transplantation $B K V$ replication.

\begin{tabular}{|c|c|c|c|}
\hline & $\begin{array}{l}B K V(-) \\
(n=512)\end{array}$ & $\begin{array}{l}B K V(+) \\
(n=41) \\
\end{array}$ & Pvalue \\
\hline \multicolumn{4}{|l|}{ Age (years) [n (\%)] } \\
\hline Mean \pm SD & $42.1 \pm 13.6$ & $42.5 \pm 1.0$ & $0.82 *$ \\
\hline Range & $9-73$ & $20-76$ & - \\
\hline \multicolumn{4}{|l|}{ Gender $[\mathbf{n}(\%)]$} \\
\hline Female & $183(35.7)$ & $11(26.8)$ & $0.25^{\dagger}$ \\
\hline Male & $329(64.3)$ & $30(73.2)$ & \\
\hline \multicolumn{4}{|l|}{ Blood Type [n (\%)] } \\
\hline $\mathbf{A}$ & $199(38.9)$ & $20(48.8)$ & $0.21^{\dagger}$ \\
\hline B & $46(9.0)$ & $1(2.4)$ & 0.24 \\
\hline $\mathbf{A B}$ & $18(3.5)$ & $2(4.9)$ & $0.65^{*}$ \\
\hline $\mathbf{O}$ & $249(48.6)$ & $18(43.9)$ & $0.56^{\dagger}$ \\
\hline \multicolumn{4}{|c|}{ Number of Transfusions [n (\%)] } \\
\hline Mean \pm SD & $1.7(3.1)$ & $1.8(2.2)$ & $0.91 *$ \\
\hline Range & $0-27$ & $0-10$ & - \\
\hline \multicolumn{4}{|l|}{ Donor type [n (\%)] } \\
\hline Living & $161(31.4)$ & $9(22.0)$ & $0.20^{\dagger}$ \\
\hline Deceased & $351(68.6)$ & $32(78.0)$ & \\
\hline \multicolumn{4}{|l|}{ ARP [n (\%)] } \\
\hline $0-50 \%$ & $476(93.0)$ & $35(85.4)$ & $0.07^{\ddagger}$ \\
\hline$>\mathbf{5 0} \%$ & $36(7.0)$ & $6(14.6)$ & \\
\hline \multicolumn{4}{|c|}{$\begin{array}{l}\text { Post-transplant kidney function [n } \\
(\%)]\end{array}$} \\
\hline Not functioning & $272(53.1)$ & $21(51.2)$ & $0.81^{\dagger}$ \\
\hline Functioning & $240(46.9)$ & $20(48.8)$ & \\
\hline \multicolumn{4}{|c|}{$\begin{array}{l}\text { Serum creatinine at discharge }(\mathrm{mg} / \\
\mathrm{dL})[\mathrm{n}(\%)]\end{array}$} \\
\hline$\leq 2.5$ & $492(96.1)$ & $37(90.2)$ & $0.09^{*}$ \\
\hline$>2.5$ & $20(3.9)$ & $4(9.8)$ & \\
\hline \multicolumn{4}{|c|}{ Immunosuppression type [n (\%)] } \\
\hline TAC & $314(61.3)$ & $32(78.0)$ & $0.03^{\dagger}$ \\
\hline MPS & $271(52.9)$ & $35(85.4)$ & $<0.01^{\dagger}$ \\
\hline
\end{tabular}

Statistical tests: * T test; ${ }^{\dagger}$ Chi-square; ${ }^{*}$ Fisher's exact. SD: standard deviation; ARP: antibody reactivity panel; TAC: tacrolimus; MPS: mycophenolate sodium. 
TABLE II

BKV replication predictors in kidney transplant patients.

\begin{tabular}{|c|c|c|c|c|}
\hline & Group & n $(\%)$ & $\begin{array}{l}\text { Odds Ratio } \\
\text { (CI 95\%) }\end{array}$ & P Value \\
\hline \multirow[t]{2}{*}{ Male gender } & BKV (-) & $329(64.3)$ & - & \\
\hline & $\mathrm{BKV}(+)$ & $30(73.2)$ & $\begin{array}{c}1.77(0.79- \\
3.85)\end{array}$ & 0.24 \\
\hline \multirow[t]{2}{*}{ Deceased donor } & BKV (-) & $351(68.6)$ & - & \\
\hline & $\mathrm{BKV}(+)$ & $32(78.0)$ & $\begin{array}{c}2.47(0.73- \\
8.31)\end{array}$ & 0.14 \\
\hline \multirow{2}{*}{$\begin{array}{l}\text { Immediate post- } \\
\text { transplant kidney } \\
\text { function }\end{array}$} & BKV (-) & $240(46.9)$ & - & \\
\hline & $\mathrm{BKV}(+)$ & $20(48.8)$ & $\begin{array}{c}1.54(0.74- \\
3.22)\end{array}$ & 0.24 \\
\hline \multirow[t]{2}{*}{$\begin{array}{c}\text { TAC } \\
\text { immunosuppression }\end{array}$} & BKV (-) & $314(61.3)$ & - & \\
\hline & $\mathrm{BKV}(+)$ & $32(78.0)$ & $\begin{array}{l}0.71(0.24- \\
2.05)\end{array}$ & 0.53 \\
\hline \multirow[t]{2}{*}{$\begin{array}{c}\text { MPS } \\
\text { immunosuppression }\end{array}$} & BKV (-) & $271(52.9)$ & - & \\
\hline & $\mathrm{BKV}(+)$ & $35(85.4)$ & $\begin{array}{c}7.96(2.35- \\
26.98)\end{array}$ & $<0.01$ \\
\hline
\end{tabular}

TAC: tacrolimus; MPS: mycophenolate sodium.

The only evaluated risk predictor in the multivariate analysis showing an association with BK viremia was the use of MPS (OR 7.96; 95\% IC 2.35 to $26.98 ; P<0.01)$. The other variables studied were not significant with regard to risk, including the male gender $(P=0.24)$, deceased donor $(P=0.14)$, immediate post-transplant kidney function $(P=0.24)$ and the use of the immunosuppressant tacrolimus (TAC; $P=0.53$ ).

Table III contains the causes associated with kidney graft loss and patient death. Of the $44(8 \%)$ graft losses in the study sample, $16(39 \%)$ occurred in patients with active BKV and eight (50\%) of these patients had post-transplant interstitial nephritis evidenced in biopsy. Seven (17\%) patients in the group with BK viremia died, whereas the mortality rate in the non-viremia group was $2.1 \%$.

The accumulated kidney graft survival probabilities in patients negative and positive for viremia were compared to investigate the effect of BKV on the kidney graft. In the absence of BKV replication, kidney graft survival at 10 years was $85.6 \%$, whereas among viremia-positive patients the survival at 10 years was $24.8 \%$. Therefore, kidney transplant recipients with BKV replication were associated with poorer graft survival $(P<0.001)$, as shown in Figure 1.

\section{DISCUSSION}

Post-transplant BKVN is a major cause of graft dysfunction and loss (Siguier et al. 2012, Mbianda et al. 2015). Kidney graft loss is attributed to the toxic effects of the virus, which causes desquamation of the epithelial cells in the urine and induces an inflammatory response that infiltrates the tubular interstices, thereby causing the development of fibrosis and tubular atrophy (Dekeyser et al. 
TABLE III

Causes of kidney graft loss and death of kidney transplant patients.

\begin{tabular}{cccc}
\hline & BKV (-) & BKV $(+)$ & Total \\
\hline Graft loss [n; (\%)] & & & \\
Interstitial nephritis & $0(0.0)$ & $8(50.0)$ & $8(18.2)$ \\
Infection & $5(17.9)$ & $1(6.3)$ & $6(13.6)$ \\
Humoral vascular & $4(14.3)$ & $1(6.3)$ & $5(11.4)$ \\
rejection & $3(10.7)$ & $1(6.3)$ & $4(9.1)$ \\
Renal vein thrombosis & $4(14.3)$ & $0(0.0)$ & $4(9.1)$ \\
Chronic rejection & $2(7.1)$ & $0(0.0)$ & $2(4.5)$ \\
Acute cellular rejection & $10(35.7)$ & $5(31.3)$ & $15(34.1)$ \\
Other causes & $28(100.0)$ & $16(100.0)$ & $44(100.0)$ \\
Total & & & \\
Death [n; (\%)] & $2(18.2)$ & $2(28.6)$ & $4(22.2)$ \\
Cardiovascular disease & $9(81.8)$ & $5(71.4)$ & $14(77.8)$ \\
Other causes & $11(100.0)$ & $7(100.0)$ & $18(100.0)$ \\
Total & &
\end{tabular}

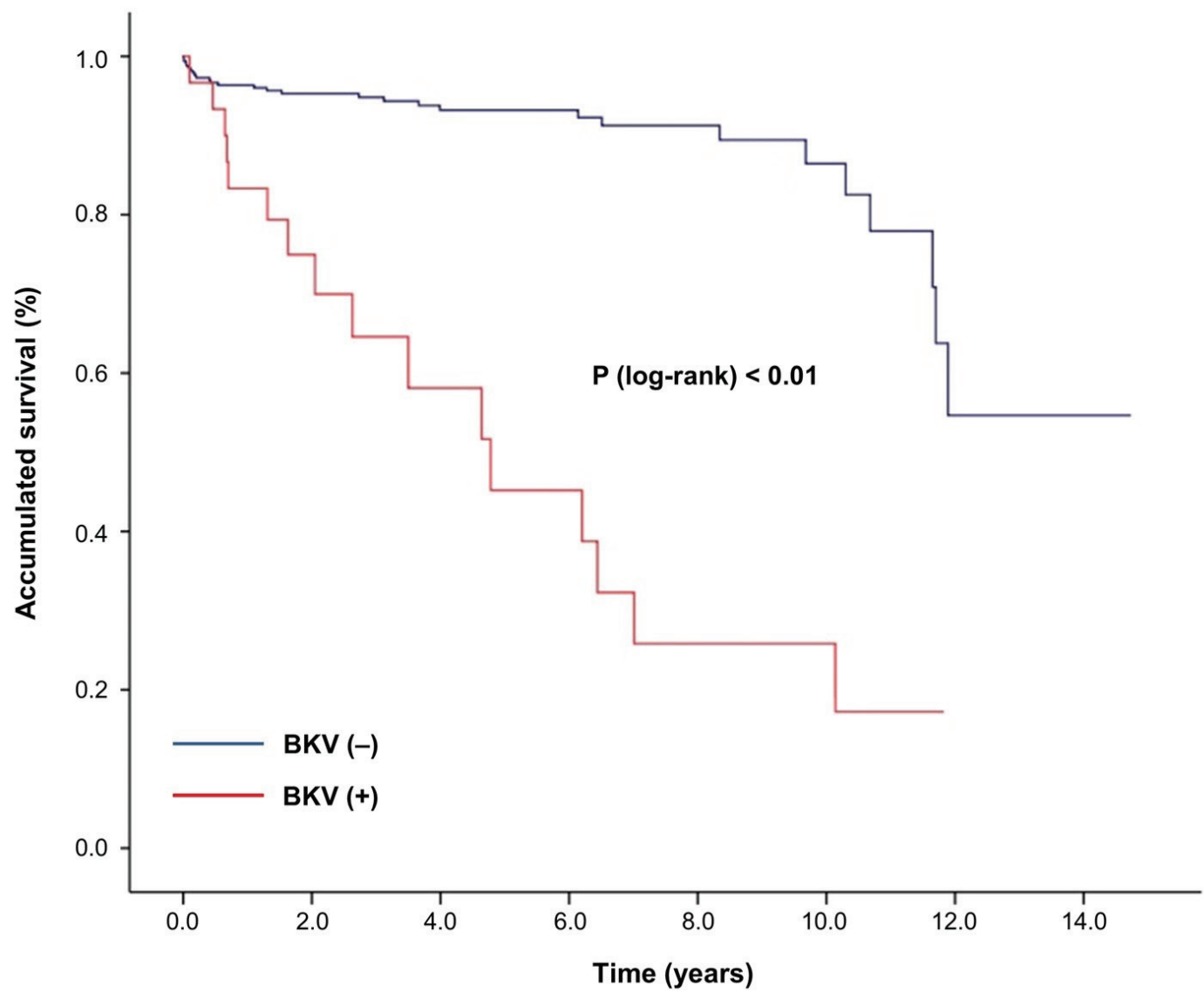

Figure 1 - Kidney graft survival in BKV-negative or -positive transplant patients. 
2015). In the present study, we demonstrated the profound effect of BK viremia on graft survival in immunosuppressed kidney transplant patients.

According to the 2014 Brazilian Transplantation Registry data from the Brazilian Organ Transplant Association, the survival of kidney grafts from living and deceased donors was $88 \%$ and $75 \%$, respectively, after 4 years (ABTO 2014). In our study, the overall survival of kidney transplant patients after 10 years of follow-up was $77.6 \%$. A significant reduction (approximately 6 years) was observed in kidney graft survival among viremia-positive patients, which confirms the serious consequences of BKVN evolution.

The prevalence of BKV replication in kidney transplants varies widely between institutions from different areas. In a study conducted in Leeds, UK, between 2006 and 2009, 12 (10.7\%) of 112 kidney transplant patients were diagnosed as BKV positive (Saundh et al. 2013). In Strasbourg, France, 48 $(20 \%)$ of 240 kidney transplant patients showed BKV replication (Borni-Duval et al. 2013). The prevalence of active BKV infection in a study in Guangzhou City, China, with 229 kidney recipients was $3.1 \%$ (Huang et al. 2014). In a study of 609 patients undergoing kidney transplantation in Ohio, United States of America (USA), between 2007 and 2011, 130 (21.7\%) patients developed BK viremia (Elfadawy et al. 2014). In turn, Schachtner et al. (2015) studied 862 kidney transplant patients in Berlin, Germany, between 2004 and 2012 and confirmed that $11.9 \%$ of the cases were BKVpositive. Montagner et al. (2010), using a qualitative seminested PCR assay, reported positivity of $43 \%$ for BKV viremia in a sample of selected renal transplant patients who presented graft dysfunction in Porto Alegre, Southern Brazil. In the present study, the prevalence of positive viral replication, which is considered a marker for the occurrence of BKVN, was $7.4 \%$. To the best of our knowledge, this is one of the first reports on the prevalence of post-kidney transplant BKV viremia in Brazil.
Uncertainty regarding the risk factors predisposing a patient to viral replication is an aggravating factor for the occurrence of BKVN (Huang et al. 2014). Medeiros et al. (2008) proposed cytomegalovirus (CMV) co-infection, the absence of the HLA-C7 allele and the donor being deceased as risk factors inherent to the donor. Factors associated with the recipient included advanced age, male gender, CMV infection, diabetes mellitus (DM), BKV seronegativity, the absence of HLA-C7 and Caucasian ethnicity. Factors directly related to the graft included a long cold ischemia time and delayed kidney function of the graft itself. In the population served in Joinville, kidney transplant patients with BK viremia were predominantly male, but there was no significant difference when compared to the group without viral replication. Likewise, the advanced age (over 60 years) mentioned in some studies as a possible risk factor showed no significance in the present study.

In a study by Huang et al. (2014), the association with BKV replication was lower in patients who received their kidneys from a living donor than in those who received a deceased donor graft. This same study also noted that kidneys transplanted from deceased donors using TAC tended to have an increased risk of BKV infection development. In the present study, most of the kidney transplant patients with BK viremia received grafts from deceased donors $(\mathrm{n}=32 ; 78 \%)$.

Risk factors for active BKV infection in the era of therapeutic drug monitoring have also not been fully identified (Sahoo et al. 2015). In some studies, the use of TAC associated with mycophenolate mofetil (MMF) was alleged to represent a high risk factor for BKV infection activation (Brennan et al. 2005, Koukoulaki et al. 2009). In another study, the incidence of BKVN was lower in subjects who received CsA and MMF than in those who did not receive this immunosuppression (Huang et al. 2014). In the present study, a strong risk association was observed between MPS-based treatment and 
active BKV infection, which corroborated the results observed by Borni-Duval et al. (2013) and Schachtner et al. (2015) in which viremia-positive patients using higher doses of mycophenolate were at increased risk of progression to BKVN.

According to Montagner et al. (2007), the immunosuppressant TAC, which is a potent calcineurin inhibitor used as prophylaxis for severe acute rejection, was strongly associated with the development of BKVN and was present in the immunosuppressant regimen of up to $70 \%$ of cases. It has been recognized that the incidence of BKVN is significantly higher in patients who received TAC than in those who received CsA (Bassil et al. 2014). In our study, a lower rate of individuals with viremia was observed among patients using CsAbased or azathioprine-based immunosuppressants. Furthermore, in contrast to previous reports, our analysis found no risk association between TAC and the occurrence of BKV replication.

Double immunosuppression based on TAC and MPS has been proposed as the most important risk factor for active BKV infection. However, this combination has been reported in any triple therapy drug regimen. Therefore, the total load of immunosuppressive drugs may be the most important risk factor (Bassil et al. 2014). Although the incidence of viremia is higher in heart transplant recipients than recipients of other organs (with the exception of kidney recipients), BKV replication appears to be a complication that predominantly affects kidney transplant recipients; therefore, the immunosuppression intensity may not be solely responsible (Mbianda et al. 2015, Viswesh et al. 2015, Kuppachi et al. 2016).

Several authors have investigated BK viremia and the progression of nephropathy. Hirsch et al. (2005) reported that graft loss reached $10 \%$ to $80 \%$ of BK-positive viremia cases. After the BKVN diagnosis, approximately half of the patients developed progressive loss of kidney graft function within two years and needed to return to kidney replacement therapy. In a more recent study, the authors noted that BKV replication had emerged as a major complication (1-10\% of cases) in kidney transplants and was responsible for graft loss in $30-80 \%$ of cases (Hirsch et al. 2013). Schachtner et al. (2015) reported that $24(2.8 \%)$ out of $103 \mathrm{BKV}$ positive patients who received a transplantation between 2004 and 2012 progressed to nephropathy, 14 died (13.6\%), 12 returned to dialysis (11.6\%) and $24(12.5 \%)$ progressed to graft loss. Elfadawy et al. (2014) stated that the graft function of BK viremiapositive patients one year after the confirmation of viremia was significantly worse, resulting in the development of BKVN in $50 \%$ of the patients. A similar study in Washington, USA, found that graft failure was high among patients with BK viremia, reaching $80 \%$ of cases (Balba et al. 2013). In our study, the overall rate of graft loss reached $8 \%$ (n $=44)$ of cases. However, $16(39 \%)$ of 41 patients with $\mathrm{BK}$ viremia progressed to the loss of the kidney graft and $7(17.1 \%)$ to death; these rates were significantly higher than those observed for BKV-negative transplant patients.

It is important to note that other factors in addition to the studied variables (i.e., the immunosuppressant dose) may have affected the occurrence of post-transplant viral replication. Moreover, the best methodological design to determine risk factors would have been the establishment of a prospective cohort study. Nevertheless, the present study sought to outline the risk factors for BKV replication and their posttransplant effect in one of the institutions performing high number of kidney transplants in Brazil. Therefore, this study constitutes unprecedented research in Latin America.

As demonstrated in the present study, kidney transplant patients are predisposed to BKV replication (particularly patients using posttransplant MPS), with a consequent reduction in kidney graft survival. Due to the absence of a specific antiviral treatment (Lebreton et al. 2016), 
the early diagnosis of BKV replication allows improving clinical and laboratory care of affected patients and makes it possible to reverse the negative effect of a modifiable factor, such as the immunosuppression regimen indicated for each case. Based on our results, we suggest that an early and periodic evaluation of viremia may contribute to the management of the anti-rejection prophylactic immunosuppression and of the evolution of BKVN, because kidney function is reversible during the early stages of lesion progression (Vasudev et al. 2005).

\section{ACKNOWLEDGMENTS}

The authors wish to thank Dr. Helbert do Nascimento Lima for helpful comments and discussion. We also thank the patients and medical staff at PróRim Foundation and the Brazilian Federal Agency for the Support and Evaluation of Graduate Education Coordenação de Aperfeiçoamento de Pessoal de Nível Superior (CAPES) for providing a scholarship to researcher EBM.

\section{REFERENCES}

ABTO - Brazilian Association of Organ Transplantation. 2014. Brazilian Transplantation Registry (2007 2014). Accessed in: 27/03/2016. Available at: http:// www.abto.org.br/abtov03_ingles/Upload/file/ BrazilianTransplantationRegistry/rbt-ingles-2014.pdf.

ALVARES J, CESAR CC, ACURCIO FA, ANDRADE EIG AND CHERCHIGLIA ML. 2011. Quality of life of patients in renal replacement therapy in Brazil: comparison of treatment modalities. Qual Life Res 21(6): 983-991.

BALBA GP, JAVAID B AND TIMPONE JR JG. 2013. BK polyomavirus infection in the renal transplant recipient. Infect Dis Clin North Am 27(2): 271-283.

BASSIL N, ROSTAING L, MENGELLE C, KALLAB S, ESPOSITO L, GUITARD J, CARDEAU-DESANGLES I, WECLAWIAK H, IZOPET J AND KAMARET N. 2014. Prospective monitoring of cytomegalovirus, Epstein-Barr virus, BK virus, and JC virus infections on belatacept therapy after a kidney transplant. Exp Clin Transplant 12(3): 212-219.

BOOTHPUR R AND BRENNAN DC. 2010. Human polyoma viruses and disease with emphasis on clinical BK and JC. J Clin Virol 47(4): 306-312.
BORNI-DUVAL C, CAILLARD S, OLAGNE J, PERRIN P, BRAUN-PARVEZ L, HEIBEL F AND MOULIN B. 2013. Risk factors for BK virus infection in the era of therapeutic drug monitoring. Transplantation 95(12): 1498-1505.

BRENNAN DC ET AL. 2005. Incidence of BK with tacrolimus versus cyclosporine and impact of preemptive immunosuppression reduction Am J Transplant 5(3): 582-594.

DEKEYSER M, FRANÇOIS H, BEAUDREUIL S AND DURRBACH AM. 2015. Polyomavirus-specific cellular immunity: from BK-virus-specific cellular immunity to BK-virus- associated nephropathy? Front Immunol 6: 307.

EGLI A, BINGGELI S, BODAGHI S, DUMOULIN A, FUNK GA, KHANNA N, LEUENBERGER D, GOSERT R AND HIRSCH HH. 2007. Cytomegalovirus and polyomavirus BK posttransplant. Nephrol Dial Transplant 22(Suppl 8): 72-82.

EL ANSARY M, ABD ELHAMID S, SAADI G, ISMAIL W, IBRAHIM N, BAHAA EL-DIN N AND ALHSYEK S. 2016. Prevalence of polyoma BK virus infection among living-donor renal transplant recipients Transpl Infect Dis 18(4): 529-537.

ELFADAWY N, FLECHNER SM, SCHOLD JD, SRINIVAS TR, POGGIO E, FATICA R, AVERY R AND MOSSAD SB. 2014. Transient versus persistent BK viremia and long-term outcomes after kidney and kidney-pancreas transplantation. Clin J Am Soc Nephrol 9(3): 553-561.

HARADA KM, MANDIA-SAMPAIO EL, DE SANDESFREITAS TV, FELIPE CR, PARK SI, PINHEIROMACHADO PG, GARCIA R, TEDESCO-SILVA HJR AND MEDINA-PESTANA JO. 2009. Risk factors associated with graft loss and patient survival after kidney transplantation. Transplant Proc 41(9): 3667-3670.

HIRSCH HH ET AL. 2005. Polyomavirus-associated nephropathy in renal transplantation: interdisciplinary analyses and recommendations. Transplantation 79(10): 1277-1286.

HIRSCH HH, RANDHAWA P AND AST INFECTIOUS DISEASES COMMUNITY OF PRACTICE. 2013. BK polyomavirus in solid organ transplantation. Am J Transplant 13(Suppl 4): 179-188.

HUANG G, ZHANG L, LIANG X, QIU J, DENG R, LI J, CHENG G, DONG Y AND CHEN L. 2014. Risk factors for BK virus infection and $\mathrm{BK}$ virus-associated nephropathy under the impact of intensive monitoring and pre-emptive immunosuppression reduction. Transplant Proc 46(10): 3448-3454.

KOUKOULAKI M ET AL. 2009. Prospective monitoring of BK virus replication in renal transplant recipients. Transpl Infect Dis 11(1): 1-10.

KUPPACHI S, KAUR D, HOLANDA DG AND THOMAS CP. 2016. BK polyoma virus infection and renal disease in non-renal solid organ transplantation. Clin Kidney J 9(2): 310-318. 
LEBRETON M, ESPOSITO L, MENGELLE C, DEL BELLO A, DELARCHE A, DÖRR G, MILONGO D, MARION O, IZOPET J AND KAMAR N. 2016. A 3-month course of ciprofloxacin does not prevent BK virus replication in heavily immunosuppressed kidney-transplant patients. J Clin Virol 79: 61-67.

MANITPISITKUL W, DRACHENBERG C, RAMOS E, MUNIVENKATAPPA R, PHILOSOPHE B, KLASSEN D AND HARIRIANA A. 2009. Maintenance immunosuppressive agents as risk factors for BK virus nephropathy: a case-control study. Transplantation 88(1): 83-88.

MBIANDA C, EL-MEANAWY A AND SOROKIN A. 2015. Mechanisms of BK virus infection of renal cells and therapeutic implications. J Clin Virol 71: 59-62.

MEDEIROS M, ALBERÚ J, GARCIA GR, FONTE E AND VELASQUEZ L. 2008. Polyoma virus in transplant recipients. Nefrologia 28: 203-211.

MONTAGNER J, MICHELON T, FONTANELLE B, OLIVEIRA A, SILVEIRA J, SCHROEDER R, NEUMANN J, KEITEL E AND ALEXANDRE CO. 2010. BKV-infection in kidney graft dysfunction. Braz J Infect Dis 14: 170-174.

MONTAGNER JM, MICHELON TF, SCHROEDER RB, FONTANELLE BT, OLIVEIRA ATD, SILVEIRA JG, GRAUDEZ MS, ALEXANDRE COP AND NEUMANN J. 2007. Polyomavirus - an emergent pathogen in transplant recipients. Einstein 5(2): 184-189.

RAMOS ET AL. 2002. Clinical course of polyoma virus nephropathy in 67 renal transplant patients. J Am Soc Nephrol 13(8): 2145-2151.
SAHOO MK ET AL. 2015. Limited variation in BK virus T-cell epitopes revealed by Next-Generation Sequencing. J Clin Microbiol 53(10): 3226-3233.

SAUNDH KB, BAKER R, HARRIS M, WELBERRY SMITH MP, CHERUKURI A AND HALE A. 2013. Early BK polyomavirus $(\mathrm{BKV})$ reactivation in donor kidney is a risk factor for development of BKV-associated nephropathy. $\mathrm{J}$ Infect Dis 207(1): 137-141.

SCHACHTNER T, BABEL N AND REINKE P. 2015. Different risk factor profiles distinguish early- onset from late-onset BKV-replication. Transpl Int 28(9): 1081-1091.

SIGUIER M, SELLIER P AND BERGMANN JF. 2012. BKvirus infections: a literature review. Med Mal Infect 42(5): 181-187.

SILVA HT, FELIPE CR, ABBUD-FILHO M, GARCIA V AND MEDINA-PESTANA JO. 2011. The emerging role of Brazil in clinical trial conduct for transplantation Am J Transplant 11(7): 1368-1375.

VASUDEV B, HARIHARAN S, HUSSAIN SA, ZHU YR, BRESNAHAN BA AND COHEN EP. 2005. BK virus nephritis: risk factors, timing, and outcome in renal transplant recipients. Kidney Int 68(4): 1834-1839.

VISWESH V, YOST SE AND KAPLAN B. 2015. The prevalence and implications of BK virus replication in non-renal solid organ transplant recipients: a systematic review. Transplant Rev (Orlando) 29(3): 175-180.

ZALONA ACJ, VARELLA RB, TAKIYA CM, GONCALVES RT, ZALIS MG AND SANTORO-LOPES G. 2013. Qualitative seminested PCR assay as an alternative to urine cytology for BK polyomavirus screening after renal transplantation. Intervirology 56(4): 249-252. 